\title{
When the Red Sox shocked the Yankees: Comparing negative and positive memories
}

\author{
ELIZABETH A. KENSINGER \\ Boston College, Chestnut Hill, Massachusetts \\ and \\ DANIEL L. SCHACTER \\ Harvard University, Cambridge, Massachusetts
}

\begin{abstract}
The present study examined whether positive or negative valence affects the amount of detail remembered about a public event, and whether positive or negative valence alters other memory characteristics (consistency, vividness, and confidence). Memory for the final game of the Boston Red Sox-New York Yankees 2004 American League playoff series was assessed in individuals who found the event highly positive, highly negative, or neutral (i.e., Red Sox fans, Yankees fans, and fans of neither team). Valence did not affect the number of personal details recalled, but it did affect memory consistency (greatest for the negative-event group) and memory overconfidence (apparent only in the positive-event group). These results indicate that positive events can be remembered with the same types of distortions that have been shown previously for negative events. Moreover, it appears that, in comparison with negative valence, positive valence sometimes can be associated with decreased memory consistency and increased memory overconfidence.
\end{abstract}

Information associated with positive or negative affect often is more likely to be recalled than information lacking emotional importance (see Buchanan \& Adolphs, 2002; Hamann, 2001). Moreover, individuals tend to believe that they remember emotional experiences more vividly than nonemotional ones. "Flashbulb memories" lie at the extreme end of the spectrum; individuals sometimes believe that they have maintained almost photographicquality memories of highly emotional, consequential, and surprising public events (see Brown \& Kulik, 1977).

In nearly all studies investigating the effects of emotion on memory for public events, researchers have assessed memory for negative events, including terrorist attacks (see, e.g., Budson et al., 2004; Paradis, Solomon, Florer, \& Thompson, 2004; Wolters \& Goudsmit, 2005), assassinations or deaths (see, e.g., Brown \& Kulik, 1977; Christianson, 1989; Pillemer, 1984), and space shuttle explosions (see, e.g., Bohannon, 1988; Kensinger, Krendl, \& Corkin, 2006). The results of these studies have demonstrated that people's memories for highly negative public events typically are associated with high vividness and confidence in memory details, although the details individuals recall are not always consistent or accurate (see Schmolck, Buffalo, \& Squire, 2000; Talarico \& Rubin, 2003). However, the research results have not provided insight into whether

This research was supported by Grants MH60941 (to D.L.S.) and MH070199 (to E.A.K.) from the National Institutes of Health. The authors thank Elizabeth Reese and Nicole Vazquez for their assistance transcribing and scoring the surveys. Correspondence concerning this article should be sent to E. A. Kensinger, McGuinn Hall, Boston College, Chestnut Hill, MA 02467 (e-mail: elizabeth.kensinger@bc.edu). these memory characteristics are similar for highly positive events and for highly negative ones.

At least in the laboratory, the mnemonic qualities associated with positive and negative affect often differ. Negative stimuli tend to be remembered with an enhanced sense of vividness and in greater detail than neutral or positive stimuli (see, e.g., Dewhurst \& Parry, 2000; Kensinger, Garoff-Eaton, \& Schacter, 2006; Ochsner, 2000). Positive stimuli, in contrast, often are remembered with only a feeling of familiarity, with general, nonspecific information (see, e.g., Bless \& Schwarz, 1999; Ochsner, 2000). Positive mood, more than negative mood, also has been associated with an increase in memory reconstruction errors. This may be because individuals in a happy mood rely either on gist-based information or on heuristics, whereas individuals in a negative mood are more likely to focus on the specific details of information (see, e.g., Bless et al., 1996; Storbeck \& Clore, 2005).

It is unclear to what degree these laboratory findings extend to real-life events infused with emotional importance. The results of research on autobiographical memory often have supported a conclusion that contrasts with results obtained via assessments of memory for stimuli presented within the laboratory: that positive memories are more vivid than negative ones (see, e.g., D'Argembeau, Comblain, \& Van der Linden, 2003; Schaefer \& Philippot, 2005; Walker, Skowronski, \& Thompson, 2003). However, the results of some studies suggest that valence has little effect on memory vividness; instead, intensity has been found to be the primary predictor of autobiographical memory characteristics (see, e.g., Talarico, LaBar, \& Rubin, 2004). Only a handful of studies have compared memories of a negative public event with memories of 
a positive event (see Berntsen \& Thomsen, 2005; Scott \& Ponsoda, 1996; Tekcan, 2001; Winograd \& Killinger, 1983). Taken together, the results of these experiments convincingly demonstrate that positive events can be associated with vivid memories. They do not, however, allow strong comparisons to be made between positively and negatively valenced memories. Positive and negative events often were not rated as equally arousing, surprising, or emotionally intense (see Berntsen \& Thomsen, 2005; Winograd \& Killinger, 1983; see also commentary by Wright \& Anderson, 1996, on Scott \& Ponsoda, 1996), were not rehearsed equally (Tekcan, 2001), and were different in their designation as either public or private events (Tekcan, 2001). These different event features make it extremely difficult for researchers to disentangle the specific effects of valence on memory. Moreover, these researchers only examined memory at one point in time, long after the event's occurrence. Although Berntsen and Thomsen used an innovative approach to examine accuracy for some contextual features by using historical records, many contextual elements of a memory (e.g., a person's location) cannot be retrospectively checked.

To our knowledge, only one prior study has examined the effects of positive versus negative valence on both the subjective vividness and the objective accuracy of adults' memories for public events (see Baker-Ward, Eaton, \& Banks, 2005 , for an investigation of children's memories). Levine and Bluck (2004) asked participants to determine whether or not particular events had occurred during the verdict decision in the O. J. Simpson trial. The critical findings from their study were that participants who were happy about the verdict were not able to discriminate true from false details of the events any better than participants who were unhappy about the verdict; yet, participants in the happy group believed they remembered the events more vividly and were more liberal in accepting the suggestion that something had occurred. These data are generally consistent with laboratory findings that show that positive mood can lead to an increased probability of memory errors (e.g., Bless et al., 1996; Storbeck \& Clore, 2005).

Like Levine and Bluck (2004), in the present study we examined memory for the same event - the final game of the 2004 Boston Red Sox-New York Yankees playoff series 1 - in participants who found the event's outcome to be highly positive (Red Sox fans), highly negative (Yankees fans), or neutral (fans of neither team). This design removed many of the potential confounds that can result from event differences (e.g., extent of media coverage, duration of event, public or private nature of event). Our study methodology differed from that of Levine and Bluck in two important ways. First, we assessed memory via cued recall rather than recognition. Recall may be more sensitive in detecting valence-based differences in memory because individuals cannot rely on familiarity alone to support their endorsement of details. Thus, to the extent that positive valence boosts familiarity-based processing whereas negative valence enhances recollective processing (see Ochsner, 2000, for evidence), the disparity in the details remembered by individuals who are happy versus unhappy about an event outcome may be greater on a task of recall than on a task of recognition. Second, although Levine and Bluck (2004) focused on memory for eventrelated details, in the present study we assessed memory for both event-related and personal details. Prior research has suggested that the aspects of an event most closely tied to the emotional response will be better remembered: Individuals who are more personally involved in an event will tend to remember more event-related details, whereas individuals less personally involved in the event will tend to remember fewer event-related details and more personal details (see, e.g., Pezdek, 2003). There also may be different resiliencies for the two types of details: Memory for event-related details sometimes declines more over time than does memory for personal details (see Smith, Bibi, \& Sheard, 2003). The studies comparing memory for eventrelated and personal details have focused on memory for negative events, however, and have left open the question of whether valence would affect the types of details most likely to be remembered (see Berntsen, 2002, for evidence that valence can selectively influence memory for particular types of details).

Thus, the present study was designed to address three main goals. First, we assessed whether the amount of detail remembered about an emotional event is affected by its valence. Second, we investigated whether valence affects a memory's vividness, its consistency, or a person's confidence in its accuracy. Third, we examined whether the effect of valence on memory differed for event-related and personal details.

\section{METHOD}

\section{Participants}

Participants were 76 young adults ${ }^{2}$ ( 40 women; ages $18-35$ ) who were recruited via fliers posted around the greater Boston area. We restricted our sample to only those individuals who had watched the game, excluding individuals who had learned about the outcome of the game in another way. We recruited participants who were strong Red Sox supporters, participants who were avid Yankees fans, and participants who described themselves as baseball fans who watched the game, but without any strong feelings about the game's outcome. ${ }^{3}$ No participants reported that they had a history of psychiatric or neurological disorder, and no participants reported that they were taking any medications at the time that would affect the central nervous system.

\section{Materials and Procedure}

Participants completed a survey that prompted them to recall the details they remembered about three events: (1) Game 7 of the 2004 playoff series between the Boston Red Sox and the New York Yankees, (2) one of the presidential debates, and (3) a nonemotional event of their choosing (see the Appendix). Only the data regarding the baseball game will be discussed here. Surveys were completed no more than 6 days after the game (Time 1) and after a 23-27 week delay (Time 2).

\section{Survey Scoring}

Time 1 surveys were scored for the quantity of information recalled. Time 2 surveys were scored for the quantity of information recalled, the consistency of that information ${ }^{4}$ (in comparison with the information provided at Time 1), the confidence in the memory, and the reported vividness of the memory. 
Quantity of recalled information. Quantity scores at Time 1 and Time 2 were calculated by tallying how many pieces of information the participants provided in response to all the event-related questions or in response to all the personal-detail questions..$^{5}$ All responses received $0,0.5$, or 1 point. A score of 0 was given when no information was recalled; 0.5 point was awarded when some information was recalled but was only partially accurate (e.g., reporting a final game score of 9 to 3 rather than 10 to 3 ) or somewhat vague (e.g., the game was watched "at home"); 1 point was given for each specific detail recalled (e.g., the game was watched from the couch). Scoring was conducted by two research assistants, and the average of the two scores was used in all analyses. Interrater reliability was high (Cronbach's $\alpha>.85$ ).

Consistency of recalled information. When the report on a piece of information was entirely different at Time 2 than at Time 1, the consistency score was 0 . When a piece of information was recalled in a slightly different manner at Time 2 than at Time 1 (e.g., eating pepperoni pizza vs. cheese pizza) 0.5 point was awarded. If exactly the same amount of detail was recalled at Time 1 and Time 2, 1 point was awarded. If participants provided additional information at Time 2, this did not impact their consistency scores. In this way, consistency at Time 2 was determined for each piece of information provided at Time 1 . Consistency scores for each question were then translated into proportions, with the sum of the consistency scores in the numerator, and the sum of the points awarded at Time 1 in the denominator. Thus, if a person recalled 2 details at Time 1 - one detail being recalled consistently at Time 1 and Time $2(=1$ point $)$ and the other detail being recalled in a slightly distorted manner $(=0.5$ point) - the consistency score would be $1.5 / 2=.75$.

So as not to confound memory distortion with forgetting, we did not include in the consistency analyses any question that remained unanswered at Time 1 or at Time 2 . Thus, a consistency score of 0 was never awarded because a person remembered nothing at Time 1 or Time 2, but rather because he or she did not remember any of the same details at both Time 1 and Time 2 .

Assessments of confidence and vividness. For each question answered at Time 2, participants were asked to rate their confidence in the response on a $1-5$ scale. ${ }^{6}$ We computed an average confidence for responses to event-related details and an average confidence for responses regarding personal details. Participants reported vividness on a $1-7$ scale.

\section{RESULTS}

\section{Emotion and Rehearsal Variables}

We first examined the scores for the emotion and rehearsal variables for the baseball game (Table 1). Participants fell into one of three categories: Those for whom the event was positive ( 41 participants [ 21 women] gave valence ratings of 5.5 or higher on a 7-point scale), those for whom the event was negative (20 participants [10 women] gave valence ratings of 2.5 or lower), and those for whom the event was neither positive nor negative $e^{7,8}$ (15 participants [9 women] gave valence ratings between 3 and 5). Intensity ratings did not significantly differ between those who found the event positive and those who found the event negative $(p>.4)$, and the nonemotional group rated the event as less intense than did either of those two groups $(t>4.5, p<.001)$. The positive and negative groups also did not differ in their ratings for personal importance of the event, surprise, number of emotions generated, or rehearsal variables (all $p s>.25$ ). For each of these variables, the individuals who found the event to be either positive or negative gave higher ratings than the individuals who found the event to be neither positive nor negative (all $p s<.05$; Table 1 ).

\section{Details Recalled}

An ANOVA was conducted with detail type (eventrelated, personal) and time $(1,2)$ as within-subjects factors and game group (positive, negative, neutral) as a between-subjects factor. This ANOVA revealed an effect of time [more details remembered at Time 1 than at Time 2; $\left.F(1,75)=74.61, p<.001, \eta_{\mathrm{p}}^{2}=.54\right]$ and of group [more details remembered by the positive and negative groups than by the neutral group; $\left.F(2,74)=5.18, p<.01, \eta_{\mathrm{p}}^{2}=.14\right]$. The ANOVA also showed an interaction between detail type and group [memory for event-related details was affected more by group status than by memory for personal details; $F(2,74)=4.89, p<.05, \eta_{\mathrm{p}}^{2}=.13$ ], between detail type and time [memory for event-related details declined more than memory for personal details over the delay; $F(1,75)=$ $\left.10.43, p<.01, \eta_{\mathrm{p}}^{2}=.14\right]$, and among detail type, time, and group $\left[F(2,74)=4.03, p<.05, \eta_{\mathrm{p}}^{2}=.11\right]$. This threeway interaction showed that, particularly at Time 2 , eventrelated details were recalled marginally better by the negative group than by the positive group $(p<.10)$, whereas the positive and negative groups recalled comparable amounts of personal detail (see Table 2 and Figure 1). It is important to note that this interaction occurred despite a comparable total number of details recalled in the two groups (collapsing across event-related and personal details, positive group recalled 17.5 details at Time 1 and 10.0 details at Time 2; negative group recalled 17.0 details at Time 1 and 11.6 details at Time 2).

Consistency. An ANOVA with detail type (eventrelated, personal) as a within-subjects factor and group (positive, negative, neutral) as a between-subjects fac-

Table 1

Mean Ratings for Rehearsal and Emotion Variables for the Game

\begin{tabular}{|c|c|c|c|c|c|c|c|c|c|c|c|c|c|c|c|c|}
\hline \multirow[b]{4}{*}{ Emotion } & \multirow{2}{*}{\multicolumn{6}{|c|}{ Rehearsal Variables }} & \multicolumn{10}{|c|}{ Emotion Variables } \\
\hline & & & & & & & \multirow{2}{*}{\multicolumn{2}{|c|}{$\begin{array}{c}\text { Personal } \\
\text { Importance } \\
\end{array}$}} & \multirow{2}{*}{\multicolumn{2}{|c|}{ Surprise }} & \multirow{2}{*}{\multicolumn{2}{|c|}{$\begin{array}{l}\text { Number of } \\
\text { Emotions } \\
\end{array}$}} & \multirow{2}{*}{\multicolumn{2}{|c|}{ Arousal }} & \multirow{2}{*}{\multicolumn{2}{|c|}{ Valence }} \\
\hline & \multicolumn{2}{|c|}{ Media } & \multicolumn{2}{|c|}{ Talk } & \multicolumn{2}{|c|}{ Think } & & & & & & & & & & \\
\hline & $M$ & $S E$ & $M$ & $S E$ & $M$ & $S E$ & $M$ & $S E$ & $M$ & $S E$ & $M$ & $S E$ & $M$ & $S E$ & $M$ & $S E$ \\
\hline Positive $(n=41)$ & 3.93 & .30 & 4.62 & .25 & 4.74 & .24 & 4.62 & .24 & 5.22 & .21 & 2.71 & .22 & 5.24 & .23 & 6.57 & .08 \\
\hline Negative $(n=20)$ & 4.07 & .43 & 5.17 & .34 & 4.52 & .38 & 4.72 & .35 & 5.52 & .37 & 2.65 & .45 & 5.47 & .35 & 1.72 & .17 \\
\hline Neutral $(n=15)$ & 2.97 & .41 & 2.70 & .40 & 2.70 & .38 & 1.97 & .28 & 4.33 & .44 & 1.17 & .34 & 2.70 & .45 & 4.43 & .15 \\
\hline
\end{tabular}

${ }^{*}$ Number of emotions reflects the total number of emotions listed by the participant. All other variables were rated using a 1-7 scale. For rehearsal, personal importance, and surprise, $1=$ low, $7=$ high. For arousal, $1=$ calming and $7=$ exciting. For valence, $1=$ negative and $7=$ positive. 
Table 2

Mean Numbers of Event-Related and Personal Details Remembered About the Game After a Short Delay

(Time 1; 1-6 Days After Game) and a Long Delay (Time 2; 23-27 Weeks After Game)

\begin{tabular}{|c|c|c|c|c|c|c|c|c|}
\hline \multirow[b]{2}{*}{ Emotion } & \multicolumn{2}{|c|}{$\begin{array}{c}\text { Event-Related } \\
\text { Details: } \\
\text { Time } 1\end{array}$} & \multicolumn{2}{|c|}{$\begin{array}{l}\text { Personal } \\
\text { Details: } \\
\text { Time } 1\end{array}$} & \multicolumn{2}{|c|}{$\begin{array}{c}\text { Event-Related } \\
\text { Details: } \\
\text { Time } 2 \\
\end{array}$} & \multicolumn{2}{|c|}{$\begin{array}{l}\text { Personal } \\
\text { Details: } \\
\text { Time } 2\end{array}$} \\
\hline & $M$ & $S E$ & $M$ & $S E$ & $M$ & $S E$ & $M$ & $S E$ \\
\hline Positive & 9.88 & .81 & 7.62 & .56 & 4.20 & .65 & 5.80 & .39 \\
\hline Negative & 10.25 & 1.16 & 6.75 & .42 & 6.32 & 1.10 & 5.31 & .33 \\
\hline Neutral & 4.32 & .72 & 6.50 & .55 & 2.19 & .45 & 4.27 & .60 \\
\hline
\end{tabular}

tor revealed a main effect of group [negative group most consistent; $\left.F(1,75)=15.48, p<.05, \eta_{\mathrm{p}}^{2}=.10\right]$ and an interaction between group and detail type [effect of group greater for personal details than for event-related details; $F(2,74)=4.21, p<.05, \eta_{\mathrm{p}}^{2}=.10$; see Table 3].

Confidence. An ANOVA with detail type (event-related, personal) as a within-subjects factor and group (positive, negative, neutral) as a between-subjects factor revealed no effect of detail type or group $\left(\eta_{\mathrm{p}}^{2}<.04\right)$ but showed an interaction between the two factors $[F(2,74)=10.56, p<$ $\left..001, \eta_{\mathrm{p}}^{2}=.24\right]$. Confidence for event-related details was marginally higher in participants who found the event to be negative $(p<.10)$, whereas confidence in the accuracy of personal details was highest in participants who found the event to be positive $(p<.01$; see Table 3$)$.

Vividness. An ANOVA with detail type (event-related, personal) as a within-subjects factor and group (positive, negative, neutral) as a between-subjects factor revealed a main effect of detail [personal details more vivid than event-related details; $F(1,73)=105.1, p<.001, \eta_{\mathrm{p}}^{2}=$ .63] but no effect of group and no interaction between group and detail $\left(\eta_{\mathrm{p}}^{2}<.05\right)$.

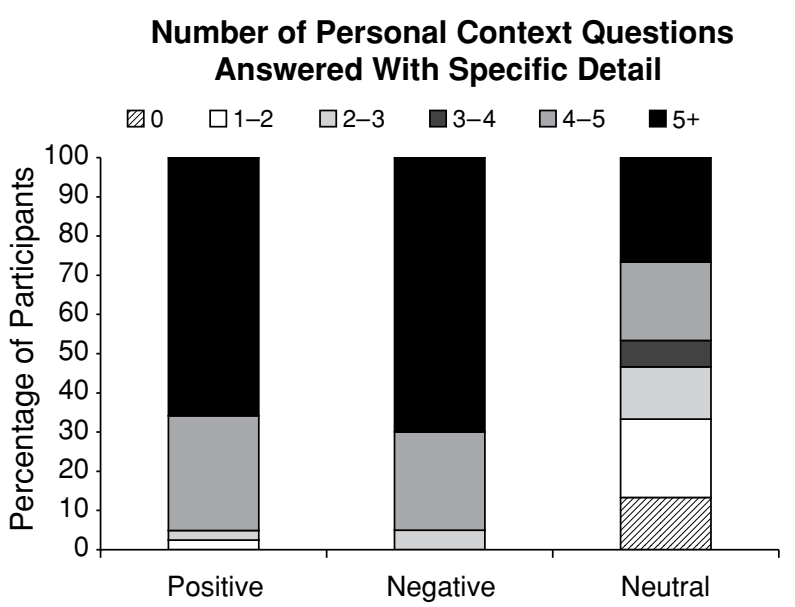

Figure 1. All participants who found the game to be positive or negative reported at least one specific personal detail after a 6-month delay, and the majority of those participants were able to recall specific details for at least five of the six personal context questions that they were asked (see the Appendix). These results suggest that, in comparison with neutral memories, both positive and negative valence enhance the amount of personal detail remembered about an event.

\section{Relation Between Consistency and Confidence}

To further explore the relation between consistency and confidence in recalled details, we computed Pearson correlations. For the positive group, ratings of confidence for event-related details correlated negatively with the consistency of the details $(r=-.39, p<.05)$, and there also was a marginal negative correlation between confidence in personal details and the consistency of those details $(r=$ $-.31, p<.10$ ). In contrast, for the negative and neutral groups, there was no correlation between the confidence in personal or event-related details and the consistency of those details $(r<.15, p>.6)$.

\section{DISCUSSION}

By assessing memory for the final game of the 2004 American League championship series between the Boston Red Sox and the New York Yankees in individuals who found the event to be highly positive (Red Sox fans), highly negative (Yankees fans), or nonemotional (fans of neither team), we examined whether the perceived valence of a public event affected the amount of information recalled or whether it influenced mnemonic qualities such as consistency of recall or confidence in a response's accuracy.

In terms of the total number of details remembered (collapsing across event-related and personal details), positive and negative valence had similar effects: Both valence groups remembered a comparable number of details, and each group remembered significantly more details than the neutral group did. However, valence did influence the type of details recalled: Although positive and negative groups remembered an equal number of personal details, the negative group remembered more event-related details than did the positive group. This finding is generally consistent with prior evidence that negative emotions enhance memory for "central" details - those tied to the emotional responsemore than do positive emotions (see, e.g., Berntsen, 2002). For the Yankees fans, it is likely that many of those "central" details were tied to the game itself rather than to the personal context.

In addition to affecting the type of details remembered, valence also affected the quality of the memories. Most notably, negative valence was associated with greater memory consistency than was positive or neutral valence. Consistency was relatively low, even for the negative group (roughly $60 \%$ of personal details recalled at Time 1 were reported in the same manner at Time 2), which is consistent with prior studies that revealed substantial memory distortions even for negative events (see Schmolck, Buffalo, \& Squire, 2000; Talarico \& Rubin, 2003). However, the present results suggest that distortion can be lower for memories of negative events than for memories of positive or nonemotional events. This finding converges with other laboratory research that has demonstrated that memories for negative information can be less prone to distortion than memories for nonemotional information (see, e.g., Kensinger \& Corkin, 2004; Kensinger, Garoff-Eaton, \& Schacter, 2006; Kensinger \& Schacter, 2006; Pesta, Murphy, \& Sanders, 2001). This finding is also consistent with 
Table 3

Mean Consistency, Confidence, and Vividness for Event-Related and Personal Details Remembered About the Game at Time 2

\begin{tabular}{|c|c|c|c|c|c|c|c|c|c|c|c|c|}
\hline \multirow[b]{3}{*}{ Emotion } & \multicolumn{6}{|c|}{ Event-Related Details } & \multicolumn{6}{|c|}{ Personal Details } \\
\hline & \multicolumn{2}{|c|}{ Consistency } & \multicolumn{2}{|c|}{ Confidence } & \multicolumn{2}{|c|}{ Vividness } & \multicolumn{2}{|c|}{ Consistency } & \multicolumn{2}{|c|}{ Confidence } & \multicolumn{2}{|c|}{ Vividness } \\
\hline & $M$ & $S E$ & $M$ & $S E$ & $M$ & $S E$ & $M$ & $S E$ & $M$ & $S E$ & $M$ & $S E$ \\
\hline Positi & .33 & .04 & 2.92 & .19 & 2.65 & .26 & .50 & .05 & 3.97 & .13 & 4.85 & .33 \\
\hline Negative & .36 & .05 & 3.25 & .17 & 2.91 & .37 & .59 & .05 & 3.26 & .11 & 4.95 & .69 \\
\hline Neutral & .30 & .05 & 3.07 & .31 & 2.10 & .28 & .44 & .06 & 2.50 & .24 & 4.16 & .35 \\
\hline
\end{tabular}

prior evidence that negative emotions can lead to fewer reconstructive memory errors than can positive emotions (see, e.g., Levine \& Bluck, 2004; Storbeck \& Clore, 2005).

To understand better the range of events for which this pattern can be observed, future studies will be needed. Talarico and Rubin (2003) reported that memories of the terrorist attacks of September 11, 2001 were less likely to be consistently remembered than memories of personal events of the participants' choosing. The divergent results may reflect methodological factors, such as the difference in the amount of time between the event and the first survey completion (1 day in Talarico \& Rubin's, [2003] study, 1-6 days in our study) and the amount of time between the event and completion of the second survey (1, 6, or 32 weeks in Talarico \& Rubin's [2003] study, 23-27 weeks in our study), or the differences in arousal between the terrorist attacks and the baseball game. The terrorist attacks of September 11,2001 were almost certainly more arousing than the Red Sox-Yankees game. It is plausible, and it has been argued previously (e.g., by Deffenbacher, 1983; Easterbrook, 1959), that up to a certain level of intensity, negative emotions enhance the ability to recall detailed information, but that at higher levels of intensity, negative emotions may begin to have a detrimental effect on memory. Future studies will be required in order to examine this hypothesis. Nevertheless, the present results are important in that they demonstrate that there are some instances in which people remember real-life negative events more consistently than they do positive or nonemotional ones.

In addition to affecting consistency, valence also influenced individuals' confidence in their memories. Those who found the event to be positive showed inflated confidence for both event-related and personal details. They had higher confidence in their responses than the negative or neutral groups did, and yet they showed an inverse relation between their confidence ratings and their response consistency. To our knowledge, this is the first demonstration that overconfidence can occur not only for highly negative events (see, e.g., Schmolck, Buffalo, \& Squire, 2000; Talarico \& Rubin, 2003) but also for highly positive ones. This finding is broadly consistent with that of Levine and Bluck (2004), who demonstrated that individuals happy about an event's outcome (the O. J. Simpson verdict) adopted a more lenient criterion when deciding whether or not something occurred. The present results further indicate that this type of distortion can occur not only for event-related details, but also for personal ones.
In summary, the present study provides evidence that events perceived as either highly positive or highly negative can be remembered with rich detail. Valence does, however, affect some memory characteristics: When an event is perceived as positive, memory appears to be more prone to inconsistencies and to overconfidence than it is when an event is perceived as negative. These results indicate that positive memories can be prone to the same types of distortion as negative ones and that memories for negative events can be less prone to such distortions than can memories for positive events. Coupled with prior studies (e.g., by Berntsen, 2002; Levine \& Bluck, 2004), these data emphasize that even in instances in which valence does not affect the overall quantity of remembered information, the qualitative nature of retrieved memories can be influenced by an event's perceived valence.

\section{REFERENCES}

BaKer-Ward, L. E., Eaton, K. L., \& Banks, J. B. (2005). Young soccer players' reports of a tournament win or loss: Different emotions, different narratives. Journal of Cognition \& Development, 6, 507-527.

Berntsen, D. (2002). Tunnel memories for autobiographical events: Central details are remembered more frequently from shocking than from happy experiences. Memory \& Cognition, 30, 1010-1020.

Berntsen, D., \& Thomsen, D. K. (2005). Personal memories for remote historical events: Accuracy and clarity of flashbulb memories related to World War II. Journal of Experimental Psychology: General, 134, 242-257.

Bless, H., Clore, G. L., Schwarz, N., Golisano, V., Rabe, C., \& WöLK, M. (1996). Mood and the use of scripts: Does a happy mood really lead to mindlessness? Journal of Personality \& Social Psychology, 71, 665-679.

Bless, H., \& Schwarz, N. (1999). Sufficient and necessary conditions in dual process models: The case of mood and information processing. In S. Chaiken \& Y. Trope (Eds.), Dual-process theories in social psychology (pp. 423-440). New York: Guilford.

Bohannon, J. N. (1988). Flashbulb memories for the space shuttle disaster: A tale of two theories. Cognition, 29, 179-196.

Brown, R., \& KulIK, J. (1977). Flashbulb memories. Cognition, 5, 7399.

Buchanan, T. W., \& Adolphs, R. (2002). The role of the human amygdala in emotional modulation of long-term declarative memory. In S. C. Moore \& M. Oaksford (Eds.), Emotional cognition: From brain to behaviour (pp. 9-34). London: John Benjamins.

Budson, A. E., Simons, J. S., Sullivan, A. L., Beier, J. S., Solomon, P. R., Scinto, L. F., ET AL. (2004). Memory and emotions for the September 11, 2001, terrorist attacks in patients with Alzheimer's disease, patients with mild cognitive impairment, and healthy older adults. Neuropsychology, 18, 315-327.

Christianson, S.-Å. (1989). Flashbulb memories: Special, but not so special. Memory \& Cognition, 17, 435-443.

Cohen, G., Conway, M. A., \& MaYlor, E. A. (1994). Flashbulb memories in older adults. Psychology \& Aging, 9, 454-463.

D’Argembeau, A., Comblain, C., \& Van der Linden, M. (2003). 
Phenomenal characteristics of autobiographical memories for positive, negative, and neutral events. Applied Cognitive Psychology, 17, 281-294.

DEFFENBACHER, K. A. (1983). The influence of arousal on reliability of testimony. In S. M. A. Lloyd-Bostock \& B. R. Clifford (Eds.), Evaluating witness evidence: Recent psychological research and new perspectives (pp. 235-251). Chichester, U.K.: Wiley.

Dewhurst, S. A., \& PARry, L. A. (2000). Emotionality, distinctiveness, and recollective experience. European Journal of Cognitive Psychology, 12, 541-551.

EASTERbrooK, J. A. (1959). The effect of emotion on cue utilization and the organization of behavior. Psychological Review, 66, 183-201.

Hamann, S. (2001). Cognitive and neural mechanisms of emotional memory. Trends in Cognitive Sciences, 5, 394-400.

Kensinger, E. A., \& Corkin, S. (2004). The effects of emotional content and aging on false memories. Cognitive, Affective, \& Behavioral Neuroscience, 4, 1-9.

Kensinger, E. A., Garoff-Eaton, R. J., \& Schacter, D. L. (2006). Memory for specific visual details can be enhanced by negative arousing content. Journal of Memory \& Language, 54, 99-112.

Kensinger, E. A., Krendl, A. C., \& Corkin, S. (2006). Memories of an emotional and a nonemotional event: Effects of aging and delay interval. Experimental Aging Research, 32, 23-45.

Kensinger, E. A., \& Schacter, D. L. (2006). Reality monitoring and memory distortion: Effects of negative, arousing content. Memory \& Cognition, 34, 251-260.

LEVINE, L. J., \& BLUCK, S. (2004). Painting with broad strokes: Happiness and the malleability of event memory. Cognition \& Emotion, 18, 559-574.

OCHSNER, K. N. (2000). Are affective events richly recollected or simply familiar? The experience and process of recognizing feelings past. Journal of Experimental Psychology: General, 129, 242-261.

Paradis, C. M., Solomon, L. Z., Florer, F., \& Thompson, T. (2004). Flashbulb memories of personal events of 9/11 and the day after for a sample of New York City residents. Psychological Reports, 95, 304310.

Pesta, B. J., Murphy, M. D., \& Sanders, R. E. (2001). Are emotionally charged lures immune to false memory? Journal of Experimental Psychology: Learning, Memory, \& Cognition, 27, 328-338.

PezDEK, K. (2003). Event memory and autobiographical memory for the events of September 11, 2001. Applied Cognitive Psychology, 17, 1033-1045.

Pillemer, D. B. (1984). Flashbulb memories of the assassination attempt on President Reagan. Cognition, 16, 63-80.

Schaefer, A., \& Philippot, P. (2005). Selective effects of emotion on the phenomenal characteristics of autobiographical memories. Memory, 13, 148-160.

Schmolck, H., Buffalo, E. A., \& Squire, L. R. (2000). Memory distortions develop over time: Recollections of the O.J. Simpson trial verdict after 15 and 32 months. Psychological Science, 11, 39-45.

ScotT, D., \& Ponsoda, V. (1996). The role of positive and negative affect in flashbulb memory. Psychological Reports, 79, 467-473.

Smith, M. C., Bibi, U., \& Sheard, D. E. (2003). Evidence for the differential impact of time and emotion on personal and event memories for September 11, 2001. Applied Cognitive Psychology, 17, 1047-1055.

Storbeck, J., \& Clore, G. L. (2005). With sadness comes accuracy; with happiness, false memory: Mood and the false memory effect. Psychological Science, 16, 785-791.

Talarico, J. M., LaBar, K. S., \& Rubin, D. C. (2004). Emotional intensity predicts autobiographical memory experience. Memory \& Cognition, 32, 1118-1132.

Talarico, J. M., \& Rubin, D. C. (2003). Confidence, not consistency, characterizes flashbulb memories. Psychological Science, 14, 455-461.

TeKcan, A. I. (2001). Flashbulb memories for a negative and a positive event: News of Desert Storm and acceptance to college. Psychological Reports, 88, 323-331.
Tekcan, A. I., \& PeynircioğLu, Z. F. (2002). Effects of age on flashbulb memories. Psychology \& Aging, 17, 416-422.

Walker, W. R., Skowronski, J. J., \& Thompson, C. P. (2003). Life is pleasant-and memory helps to keep it that way! Review of General Psychology, 7, 203-210.

Winningham, R. G., Hyman, I. E., JR., \& Dinnel, D. L. (2000). Flashbulb memories? The effects of when the initial memory report was obtained. Memory, 8, 209-216.

Winograd, E., \& Killinger, W. A., JR. (1983). Relating age at encoding in early childhood to adult recall: Development of flashbulb memories. Journal of Experimental Psychology: General, 112, 413-422.

Wolters, G., \& Goudsmit, J. J. (2005). Flashbulb and event memory of September 11, 2001: Consistency, confidence and age effects. Psychological Reports, 96, 605-619.

Wright, D. B., \& Anderson, S. J. (1996). Comments on Scott and Ponsoda's (1996) positive and negative flashbulb memories. Psychological Reports, 79, 1169-1170.

\section{NOTES}

1. We consider this game to be a highly emotional public event for Red Sox and Yankees fans because of the intense nature of the Red SoxYankees rivalry, the national attention focused on this series, and the surprising and unprecedented outcome in which the Red Sox reversed decades of defeat and won the series, thereby becoming the first team in baseball history to overcome a 3-0 game deficit and win the series.

2 . We included only young adults in this study because prior research has suggested that aging may impact a person's ability to remember emotional events vividly (see, e.g., Cohen, Conway, \& Maylor, 1994; Tekcan \& Peynircioğlu, 2002).

3 . Because of the large number of college students in our sample, team affiliation of participants tended to be associated with their hometown (e.g., most of the Yankees fans had grown up in the New York area; many individuals who were neither Red Sox nor Yankees fans closely followed the games of their hometown team).

4. It is important to note that while consistency for personal details can be assessed in this study, accuracy cannot. Surveys were not filled out immediately after the game's termination, and therefore it is possible that some distortions were present upon first survey completion (see Winningham, Hyman, \& Dinnel, 2000).

5. For event-related details, points were only awarded for information known to be accurate. Because accuracy could not easily be assessed for personal details, scores were awarded for each specific personal detail recalled.

6. Instances in which participants qualified an answer and then gave it high confidence were excluded from analyses (e.g., one participant responded "I may have been wearing jeans" and then gave that response the highest confidence).

7. As with many real-life emotional events, the emotionality of this event likely developed and changed during the course of its duration. It is impossible to know whether the event became positive or negative only upon its termination (i.e., when the final outcome was known), or whether, because this was the last in a series of games in which the Red Sox had enjoyed a tremendous comeback, the valence was in some way established before the game's completion. This ambiguity is only critical to the extent that it is tempting to claim that valence exerts its effects during encoding rather than during consolidation or retrieval. We make no claims about during which memory phase valence exerts its effects because it is often difficult to disentangle encoding, consolidation, and retrieval effects in behavioral studies of emotional memory. But given prior evidence that participants' mood at retrieval can influence memory accuracy (see, e.g., Levine \& Bluck, 2004), it is certainly plausible that effects aside from those operating at encoding mediated the valence effects seen here.

8. A potential limitation of this study is that we had fewer participants in the negative and the neutral groups than in the positive group. 
APPENDIX

Questions Included on the Survey

\section{Event-Related Questions ${ }^{\mathrm{A}}$}

\section{Questions About Game}

When was the game?

Who won the game?

What was the final score?

What were the important plays?

Who pitched for the Red Sox?

Who pitched for the Yankees?

Who hit the home runs?

What time did the game end?

Where were you?

Who were you with?

What were you wearing?

What were you eating/drinking?

What did you do after the event?

Do you remember any other information about what you were doing (or your surroundings) during the event?

\section{Assessments of Memory Vividness}

(Asked Only at Time 2)

How vividly do you remember the event? (1-7 scale)

How vividly do you remember your activities and location during the event? (1-7 scale)

\section{Assessments of Emotional Importance ${ }^{\mathrm{A} 3}$ \\ (Same for All Events)}

What was the intensity of your emotional reaction to the event? (1-7 scale)

Was your reaction positive or negative? (1-7 scale)

What was the personal importance of the event? (1-7 scale)

What was the broader importance of the event? (1-7 scale)

How surprising was the outcome of the event? (1-7 scale)

What emotions were generated for you by this event (list all that apply)? (1-7 scale)

\section{Assessments of Rehearsal \\ (Same for All Events)}

How frequently have you thought about this event since it occurred? (1-7 scale)

How frequently have you watched/read/listened to media coverage about this event? (1-7 scale)

How frequently have you spoken about this event? (1-7 scale)

\section{Group Affiliation}

Which best describes you (1-7 scale): Which best describes you (1-7 scale):

$$
1=\text { strong Yankees fan } \quad 1 \text { strong Democrat }
$$$$
7 \text { = strong Red Sox fan } \quad 7 \text { = strong Republican }
$$

\section{NOTES}

A1. At Time 2, participants were also asked to report their confidence in the accuracy of their response to each eventrelated and personal detail question (using a 1-5 scale).

A2. At Time 2, participants were given a 2-4 word cue for the event, based on the description that they had supplied at Time 1.

A3. At Time 2, separate questions were asked about the time immediately following the event and about the current time (e.g., What was the intensity of your emotional reaction immediately after the event? What is the intensity of your emotional reaction to the event now?).

(Manuscript received October 2, 2005

revision accepted for publication March 21, 2006.) 